\title{
INFLUÊNCIA DA IDADE NA RESISTÊNCIA NATURAL DA MADEIRA DE Eucalyptus grandis W. Hill ex. Maiden AO ATAQUE DE CUPIM DE MADEIRA SECA (Cryptotermes brevis) ${ }^{1}$
}

\author{
José de Castro Silva², Antônio Gonzalo Caballeira Lopez ${ }^{3}$, José Tarcísio da Silva Oliveira ${ }^{4}$
}

\begin{abstract}
RESUMO - Este trabalho objetivou testar a resistência natural da madeira de Eucalyptus grandis de quatro diferentes idades $(10,14,20$ e 25 anos) ao ataque de cupins de madeira seca. As amostras foram retiradas da prancha diametral, na região próxima ao cerne mais externo, em número de seis unidades por tora, de cada uma das 16 árvores (quatro de cada idade). Cada par de amostras foi colocado em contato com 40 indivíduos, da espécie Cryptotermes brevis (cupim de madeira seca), avaliando-se cada par comparativamente com corposde-prova de madeira altamente suscetível ao ataque de cupins, no caso a madeira de Pinus elliottii, sob idênticas condições laboratoriais, mediante observações em intervalos periódicos. Ao término do ensaio foram registrados a porcentagem de cupins mortos e o número de furos, além do desgaste produzido por esses insetos. Verificouse que a madeira de 10 anos foi a mais severamente atacada, com desgaste semelhante ao da testemunha. As madeiras de 14, 20 e 25 anos não diferiram estatisticamente entre si, quanto à resistência natural ao ataque de cupim de madeira seca, todas classificadas como de desgaste acentuado. A madeira de todas as idades mostrouse altamente suscetível ao ataque de cupins, revelando a baixa resistência natural da espécie.
\end{abstract}

Palavras-chave: Eucalyptus grandis, madeira, cupins de madeira seca, Cryptotermes brevis.

\section{TREE AGE INFLUENCE ON Eucalyptus grandis WOOD NATURAL RESISTANCE TO DETERIORATION BY DRY-WOOD TERMITES}

\begin{abstract}
The objective of this work was to evaluate the variability in the resistance to dry-wood termites of Eucalyptus grandis wood from commercial stands of four different ages (10, 14, 20 and 25 years old). Two logs were cut from sixteen different trees, four of each age. Six pairs of samples were taken from the most recent heartwood of a central board of a log. Each pair of samples was put in contact with 40 drywood termite individuals, Cryptotermes brevis. Samples of Pinus elliottii, a highly susceptible species, were also offered to the insects at the same time and under the same laboratory conditions in order to compare the results. The assay lasted for 45 days. After this period, the remaining insects were counted and the wood samples were inspected to determine number of holes, damage etc. It was found that 10-year-old wood samples were the most severely attacked, being the damage similar to that suffered by the control. There was no significant difference between levels of damage suffered by the other three treatments (trees of 14, 20 and 25 years of age); in all cases the damage caused by the insects was considered very serious.
\end{abstract}

Key words: Eucalyptus grandis, dry-wood-termite, Cryptotermes brevi.

\footnotetext{
${ }^{1}$ Recebido para publicação em 13.11.2002 e aceito para publicação em 10.8.2004.

${ }^{2}$ Departamento de Engenharia Florestal da UFV. E.mail: <jcastro@ufv.br>.

${ }^{3}$ Instituto de Pesquisas Tecnológicas de São Paulo.

${ }^{4}$ Departamento de Engenharia Rural da UFES. E.mail: <jcsilva@npd.ufes.br>.
} 


\section{INTRODUÇÃO}

Um dos fatores que limitam a utilização da madeira para diversas finalidades é, sem dúvida, a sua baixa durabilidade natural. $\mathrm{O}$ conhecimento da resistência natural de madeiras ao ataque de organismos xilófagos, principalmente cupins, torna-se um requisito muito importante para a utilização correta da madeira, principalmente nas indústrias de movelaria e na construção civil.

Segundo Oliveira (1997), determinada madeira terá preferência em relação às demais quanto maior for a sua durabilidade natural, pois se evitariam os inconvenientes advindos da utilização de produtos químicos, alguns bastante tóxicos, empregados no tratamento de madeiras de baixa durabilidade, a fim de lhe conferir um desempenho satisfatório em serviço. Além das restrições ambientais aos produtos que hoje dominam a indústria da preservação, são relevantes alguns aspectos técnicos, relacionados à própria madeira a ser preservada. Tais aspectos estão relacionados à resistência de impregnação da madeira de certas espécies, como é o caso do cerne de eucalipto.

Segundo Oliveira et al. (1986), a madeira é degradada biologicamente, porque alguns organismos utilizam os polímeros naturais da sua parede celular como fonte de alimento e possuem sistemas enzimáticos específicos, capazes de metabolizá-los em unidades digeríveis. O alburno é a parte da madeira que apresenta material nutritivo armazenado, o que o torna mais suscetível ao ataque de agentes biológicos. O cerne normalmente apresenta maior durabilidade natural, devido à ausência de material nutritivo e, principalmente, à presença de extrativos. Segundo esses autores, os cupins, ou térmitas, são os principais insetos xilófagos, considerados hemimetábolos, eussociais e, predominantemente, tropicais. Segundo Déon (1989), os térmitas de madeira seca são ativos destruidores de madeira, mesmo formando colônias com relativamente poucos indivíduos.

Os cupins pertencem à ordem Isoptera, sendo atualmente conhecidas quase três mil espécies. Os cupins de madeira seca pertencem à família Kalotermitidae, que engloba várias espécies, entre elas Cryptotermes brevis, que vive exclusivamente dentro da madeira da qual se alimentam, formando colônias. Do ponto de vista econômico, tal espécie é a mais importante no Brasil. Lepage (1986) afirmou que os cupins desse grupo instalam suas colônias em peças de madeira, com baixos teores de umidade, variando de 10 a $12 \%$, e não exigem contato com o solo. Iniciando o ataque após a revoada, cada par sexuado dessa espécie penetra na madeira, através de rachaduras ou de outras aberturas naturais, e inicia a escavação para o interior, fechando a entrada com uma secreção intestinal. Durante a escavação das galerias, os cupins de madeira seca eliminam pequenos resíduos fecais, através de orifícios abertos temporariamente, o que ajuda na detecção do ataque dos térmitas.

Pesquisadores brasileiros e de outras partes do mundo têm-se preocupado com o problema dos cupins. Lelis (1994) estimou um prejuízo de US\$ 3,5 bilhões ao realizar um levantamento em 240 edificações na cidade de São Paulo, no período de 1973 a 1993; segundo ele, o dano real causado pelos térmitas é, ainda, desconhecido. Serpa (1986) constatou a presença de térmitas do gênero Cryptotermes destruindo obras sacras, molduras de quadros, altares, vigas, caibros, ripas e constituintes do madeiramento das coberturas das edificações da cidade histórica de Olinda, em Pernambuco.

Cañedo e Lelis (1985) testaram, em laboratório, várias espécies de folhosas ao ataque de Cryptotermes brevis, visando à indicação de espécies de madeira para a produção de cruzetas, em substituição à perobarosa (Aspidosperma polyneuronMuell. Arg.). Relatando experiências em laboratório e avaliando a suscetibilidade de 35 espécies de madeiras da Amazônia ao ataque de Cryptotermes brevis, esses autores informaram que cinco foram suscetíveis, nove resistentes e as 21 espécies restantes apresentaram níveis intermediários de resistência.

No Brasil, pouco ou quase nada se conhece a respeito do comportamento real da madeira das espécies do gênero Eucalyptus em relação à resistência ao ataque de cupins. Poucos estudos foram desenvolvidos, e os resultados revelaram que algumas espécies são mais suscetíveis a tais insetos que outras, mas, no geral, todas apresentaram resistência natural variando de baixa a moderada. Rudman e Gay (1967) estudaram, em laboratório, a suscetibilidade da madeira do cerne e do alburno de Eucalyptus marginata Donn ex Sm. ao ataque de duas espécies de cupins subterrâneos. Após 56 dias de exposição, os autores encontraram variações quanto ao grau de ataque nas diferentes posições, a partir da medula para a casca. Observaram, 
ainda, que as árvores mais jovens e provenientes de rápido crescimento apresentaram melhor desempenho quanto à resistência ao ataque, em relação às árvores de maior idade, provenientes de povoamentos naturais. Oliveira (1997), estudando o comportamento da madeira de sete espécies de eucalipto, verificou que as madeiras de Eucalyptus grandis e Eucalyptus urophylla S.T. Blake foram altamente suscetíveis ao ataque de cupim de madeira seca, em condições laboratoriais. Esse mesmo autor notou que as madeiras de Eucalyptus microcorys F. Muell., Corymbia citriodora (Hook.) K.D. Hill \& L.A.S. Jhonson e Eucalyptus cloeziana F. Muell. apresentaram elevada resistência ao ataque de cupins, confirmando, inclusive, várias citações da literatura. Tal resultado se mostrou correlacionado com a baixa massa específica e, principalmente, ao teor de extrativos, permitindo concluir que, quanto mais elevados forem a massa específica e, principalmente, o teor de extrativos, mais reduzido será o desgaste provocado pelos cupins de madeira seca. Os resultados obtidos pelo referido autor permitiram-no credenciar as últimas madeiras para o uso na construção civil. Segundo IPT (1989), o alburno da madeira de Eucalyptus grandis, E. urophylla e $C$. citriodora apresentou baixa resistência ao ataque de cupins de madeira seca. No caso específico doEucalyptus grandis, até mesmo o cerne exibiu elevado desgaste. Comparada com as demais espécies em questão, tal espécie foi a que exibiu menor resistência natural.

Este trabalho teve como objetivo avaliar a resistência natural da madeira de Eucalyptus grandis, de quatro diferentes idades (10, 14, 20 e 25 anos), ao ataque de cupins de madeira seca (Cryptotermes brevis).

\section{MATERIAL E MÉTODOS}

O material utilizado neste estudo foi obtido de plantios comerciais de Eucalyptus grandis Hill ex. Maiden, com idades de 10, 14, 20 e 25 anos, procedentes da Fazenda Monte Alegre, da KLABIN Fabricadora de Papel e Celulose S. A., localizada no município de Telêmaco Borba, no Estado do Paraná. As amostras foram retiradas da prancha diametral, na região próxima ao cerne mais externo, em número de seis unidades por tora, de cada uma das 16 árvores (quatro de cada idade). No ensaio de resistência natural ao ataque de cupim de madeira seca, utilizou-se o método desenvolvido no Instituto de Pesquisas Tecnológicas do Estado de São Paulo, denominado "Ensaio Acelerado de Laboratório da Resistência Natural ou de
Madeira Preservada ao Ataque de Térmitas do Gênero Cryptotermes, da Família Kalotermitidae" (IPT, 1980). As amostras apresentaram dimensões nominais de $2,3 \times 0,6 \times 7,0 \mathrm{~cm}$, sendo a maior dimensão correspondente ao sentido longitudinal, paralela à grã da madeira. Cada par de amostras foi colocado em contato com 40 indivíduos da espécie Cryptotermes brevis, família Kalotermitidae, na razão de 39 pseudo-operários e um soldado. A avaliação foi feita comparativamente com corposde-prova de madeira altamente suscetível ao ataque de cupins, no caso a madeira de Pinus elliottii, sob idênticas condições laboratoriais. O ensaio foi instalado em câmara climatizada, sob a temperatura de $27,0{ }^{\circ} \mathrm{C}$ e umidade relativa de $70 \%$, por um período de 45 dias, fazendo-se observações em intervalos periódicos. Ao término do ensaio foram registrados a porcentagem de cupins mortos e o número de furos, bem como atribuídas notas para o desgaste produzido. As notas variaram de 0 (zero) a 4 (quatro), com a seguinte correspondência: a) 0 = nenhum dano; b) 1 = dano superficial; c) 2 = dano moderado; d) 3 = dano acentuado; e e) 4 = dano profundo - correspondente ao desgaste observado na testemunha.

A variável de resposta analisada foi o dano provocado pelos cupins, segundo o critério subjetivo de notas de três avaliadores, mencionado anteriormente. Os resultados foram analisados estatisticamente, com significância de 5\%. Utilizou-se a análise de variância não-paramétrica (ANOVA) de KruskalWallis para avaliar o fator amostra, segundo a variável idade. A comparação entre os vários níveis foi feita pelo teste não-paramétrico de Mann-Whitney.

\section{RESULTADOS E DISCUSSÃO}

Os resultados do ensaio de resistência da madeira de Eucalyptus grandis, de diferentes idades, ao cupim de madeira seca (Cryptotermes brevis) estão apresentados na Tabela 1 .

Os valores encontrados com relação ao dano em Eucalyptus grandis provocado pelo ataque do cupim de madeira seca (Cryptotermes brevis) estão em conformidade com os normalmente encontrados na literatura. Na Tabela 1, verifica-se que a madeira de Eucalyptus grandis, independentemente da idade, é altamente suscetível ao ataque de cupim de madeira seca, uma vez que o dano apresentado em todas as idades ficou muito próximo daquele sofrido pela madeira que serviu de testemunha. Todas as amostras

R. Árvore, Viçosa-MG, v.28, n.4, p.583-587, 2004 
apresentaram uma injúria que variou de acentuada a profunda, segundo a norma IPT (1980). O índice de mortalidade dos insetos foi reconhecidamente alto, talvez devido à presença de extrativos tóxicos na madeira, inclusive naquela utilizada como testemunha. Os dados apresentados pela análise de variância indicaram a influência da idade no dano sofrido pela madeira, ressaltando-se que a madeira de 10 anos não apresentou diferenças significativas em relação à testemunha, mas ambas diferiram estatisticamente das demais idades.

A Figura 1 ilustra a tendência de variação no dano das peças em relação às diferentes idades.

Tabela 1 - Valores médios da porcentagem de cupins mortos e dano em Eucalyptus grandis de diferentes idades

Table 1-Meam values of died termite percentage and damage of Eucalyptus grandis at different ages

\begin{tabular}{ccccc}
\hline $\begin{array}{c}\text { Idade } \\
\text { (anos) })\end{array}$ & $\begin{array}{c}\text { Cupins } \\
\text { Mortos }(\%)\end{array}$ & Desgaste & Médias \\
\hline 20 & 47 & 3,0 & $\mathrm{a}^{(1)}$ & \\
25 & 46 & 3,0 & $\mathrm{a}$ & \\
14 & 48 & 3,2 & $\mathrm{a}$ & \\
10 & 42 & 4,0 & & $\mathrm{~b}$ \\
Testemunha $^{(2)}$ & 36 & 4,0 & & $\mathrm{~b}$ \\
\hline
\end{tabular}

(1) Médias seguidas da mesma letra não diferem estatisticamente, pelo teste de Mann-Whitney com significância de 5\% $(\mathrm{p}<0,05)$

(2) A testemunha corresponde à madeira de Pinus elliottii.

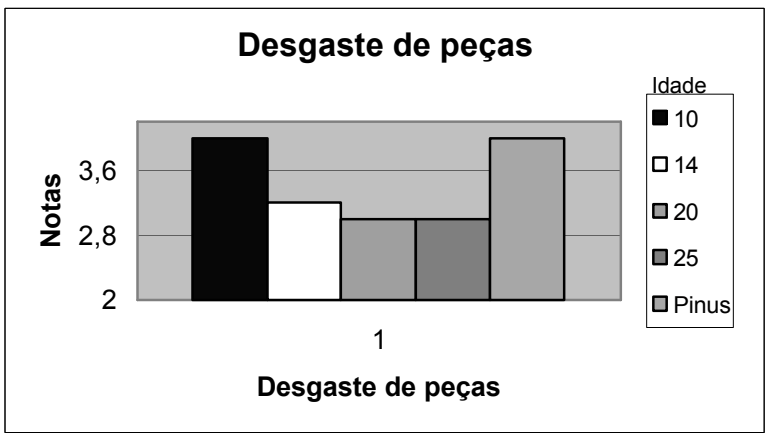

Figura 1 - Notas relativas ao dano produzido em Eucaliptus grandis, de diferentes idades (anos), pelo cupim de madeira seca (Cryptotermes brevis).

Figure 1 - Notes atributed to the damage to Eucaliptus grandis, at four different ages (years), by dry-wood termite (Cryptotermes brevis).
Como era esperado, a madeira de 10 anos foi mais severamente atacada que a das demais idades, em razão da menor porcentagem de extrativos e da maior quantidade de carboidratos. Acredita-se que maior quantidade de extrativos em madeiras mais velhas, bem como sua natureza polifenólica, confere-lhe maior poder inseticida, resultando em maior resistência ao ataque de cupins. A madeira de 10 anos apresentou o mesmo comportamento da de Pinus elliottii, altamente suscetível ao ataque de cupins. As madeiras de 14, 20 e 25 anos não diferiram estatisticamente entre si, quanto à resistência natural ao ataque de cupim de madeira seca, mas se mostraram bastante suscetíveis ao ataque de cupins, sendo todas classificadas como de dano acentuado.

\section{CONCLUSÕES}

Com base nos resultados, pode-se concluir que:

a) A madeira de 10 anos, em relação às de demais idades, foi mais severamente atacada pelo cupim de madeira seca (Cryptotermes brevis).

b) As madeiras de 14, 20 e 25 anos não tiveram diferenças entre si, em relação ao ataque porCryptotermes brevis, embora todas elas apresentassem alta suscetibilidade ao ataque.

c) A espécie Eucalyptus grandis, independentemente das diferentes idades testadas, mostrou-se altamente suscetível ao ataque porCryptotermes brevis, apresentando resultados bastante semelhantes aos encontrados na madeira de Pinus elliottii.

\section{AGRADECIMENTOS}

Os autores agradecem à KLABIN Fabricadora de Papel e Celulose S.A. e ao Instituto de Pesquisas Tecnológicas de São Paulo, por terem viabilizado este trabalho, através de cessão da madeira e de seus laboratórios.

\section{REFERÊNCIAS BIBLIOGRÁFICAS}

\section{CAÑEDO, M.D.; LELIS, A. T. Laboratory \\ tests on material resistence to Cryptotermes brevis(Walker) attack of native hardwoods for crossarms production. São Paulo, IPT, 1985. 7p.}

DEON, G. Manual de preservação de madeiras em clima tropical. Centre Techinique Forestier Tropical, 1989, 116p. 
INSTITUTO DE PESQUISAS TECNOLÓGICAS. IPT. Métodos de ensaios e análise em preservação de madeira: ensaio acelerado de laboratório da resistência natural ou de madeira preservada ao ataque de térmitas do gênero Cryptotermes (Fam. Kalotermitidae). São Paulo: 1980. 1 p. (Publicação IPT, 1157)

INSTITUTO DE PESQUISAS TECNOLÓGICAS. IPT. Caracterização tecnológica de madeira de eucalipto para utilização no setor habitacional, 1989. 24p. (Relatório, 27355)

LELIS, A . T. Termite problem in São Paulo city Brazil. In: CONGRESS OF THE INTERNATIONAL UNION FOR THE STUDY OF SOCIAL INSECTS, 12., 1994, Paris. Proceedings... Paris: 1994, p. 42-46.

LEPAGE, E. S. Química da madeira. In: MANUAL de preservação de madeiras. São Paulo: IPT, 1986. p. 69-97.
OLIVEIRA, A. M.F. et al. Agentes destruidores da madeira. In: MANUAL de preservação de madeiras. São Paulo: 1986. p. 99-275.

\section{OLIVEIRA, J. T. S. Caracterização da}

madeira de eucalipto para a construção civil. 1997, 429f. Tese( Doutorado) - Universidade de São Paulo, São Paulo, 1997.

RUDMAN, P.; GAY, F.J. Causes of natural durability in timber and causes of variation in the termite resistence of jarrah(Eucalyptus marginata Sm.) Holzforschung, v.21, p.21-23, 1967

SERPA, F.G. Cupim, uma ameaça a Olinda, patrimônio da humanidade. São Paulo: ABPM, 1986. 8 p. (Boletim, 40). 